\title{
Dynamics of water vapor adsorption on humidity-indicating silica gel
}

\author{
Devrim Balköse ${ }^{\text {a, * }}$, Sevgi Ulutan ${ }^{\text {a }}$, Fehime Çakıcıoğlu Özkan ${ }^{\text {a }}$, Sedat Çelebi ${ }^{\text {b }}$, \\ Semra Ülkü c \\ ${ }^{a}$ Ege University, Faculty of Engineering, Department of Chemical Engineering, Bornova, İmir, Turkey \\ ${ }^{\mathrm{b}}$ Ege University, Science Faculty, Department of Chemistry, Bornova, Izmir, Turkey \\ c Izmir Institute of Technology, Alsancak, İmir, Turkey
}

Received 22 May 1997; accepted 31 March 1998

\begin{abstract}
Well-defined $\mathrm{CoCl}_{2}$-containing silica gels were prepared by impregnation of the aqueous solution of the salt to silica hydrogel, drying and aging methods. Silica gels having $392-437 \mathrm{~m}^{2} \mathrm{~g}^{-1}$ surface area and $0.21-0.37 \mathrm{~cm}^{3} \mathrm{~g}^{-1}$ pore volume and having an average particle size of $3 \mathrm{~mm}$ were obtained. Aging in $\mathrm{CoCl}_{2}$ solutions decreased the surface area of silica gels from $540 \mathrm{~cm}^{2} \mathrm{~g}^{-1}$ to $392-430 \mathrm{~m}^{2} \mathrm{~g}^{-1}$ and pore volume from 0.27 to $0.21-0.23 \mathrm{~cm}^{3} \mathrm{~g}^{-1}$ for $\mathrm{CoCl}_{2}$ concentration smaller than $0.28 \mathrm{~mol} \mathrm{dm}^{-3}$ in silica gel. Adsorbed water desorbed from the gels absorbing $1917-2555 \mathrm{~J} \mathrm{~g}^{-1}$ energy as determined by differential scanning calorimetry. The $\mathrm{CoCl}_{2}$-containing gels were successfully used in dynamic column experiments, with linear relation between velocities of inlet air and movement of blue to pink boundary. The colour change also makes the detection of the defects in column filling which causes air channelling. (C) 1998 Elsevier Science B.V. All rights reserved.
\end{abstract}

Keywords: Column dynamics; Humidity-indicating; Silica gel; Cobaltous chloride; Water vapor adsorption

\section{Introduction}

Cobalt(II) salts dispersed on different substrates have functions as humidity-indicating desiccants and catalysts. Monitoring the humidity of a gas stream by visual observation of the colour of humidity indicators is extensively used in industry. The breakthrough curves from the air drying columns could be predicted by using models based on adsorption isotherm and effective diffusion coefficient of water

\footnotetext{
* Corresponding author.
}

vapor in the adsorbent and heat of adsorption [1]. The model calculation of the breakthrough curves will not be possible if channelling of air through the column occurs due to packing irregularities. Thus humidity-indicating adsorbents can be used to detect channelling. Dry regions created by channelling of the air in the column will remain blue, while the other region turns pink.

Humidity indicators sold in the market are based on cobaltous salts mixed with desiccants such as silica gel, calcium sulfate, polyvinyl pyrollidon, clay and alumina. The colour of these indicators change from blue to pink on water vapor adsorption. Opti- 
mizing the type of the substrate and the type and concentration of the cobalt salt, it is possible to produce indicators which show a sharp colour change in a small humidity range. Cobalt(II) chloride-containing indicators on silica gel carrier are sold in the market under trade names Merck, Davison and Matrex. Drierite is also a desiccant with calcium sulfate carrier.

There are controversial explanation of the colour change of cobaltous salts mixed with adsorbents. Hataway and Lewis [2] studied the mechanism of the colour inversion for cobaltous nitrate-impregnated silica gels and concluded that in wet state cobalt(II) ions are in the same complex structure as in aqueous environment and they coordinate with the surface oxygen atoms of silica in dry state. On the other hand, the colour change of cobaltous chloride mixed with clay is attributed to the complex formation between $\mathrm{Co}$ (II) ions and monomeric silisilic acid formed due to hydrolysis of clay [3]. Formation of tetrachloro cobalt(II) ions in dry state is another explanation present in the literature [4]. Presence of anhydrous cobaltous chloride in dry state is another possible reason of the blue colour. The species formed by the colour transition can be identified by means of their visible spectra [2,5,6]. The absorption maxima of $\mathrm{CoCl}_{2}, \mathrm{CoCl}_{2} \cdot 2 \mathrm{H}_{2} \mathrm{O}, \mathrm{CoCl}_{2} \cdot 6 \mathrm{H}_{2} \mathrm{O}$, $\mathrm{Co}\left(\mathrm{H}_{2} \mathrm{O}\right)_{6}^{++}, \mathrm{Na}_{2} \mathrm{CoSiO}_{4}$ and $\mathrm{Co}(\mathrm{II})$ on silica gel were reported in Refs. [7-10]. There are also studies involving eye inspection of the colour in cobalt(II)containing silica gels [4].

Measurement of the adsorption isotherm of water vapor on carrier with and without the cobalt salt was used to find out the degree of hydration of the salt. Cobaltous chloride having more than 9 moles of water was identified by this method [5].

The form of active component present in humidity indicators affects the indicating function. Monolayer dispersion of a salt on an inorganic support is the thermodynamically favoured process. There is a strong X-ray diffraction evidence of monolayer or sub-monolayer dispersion of cobaltous salts on the surface of alumina carrier [11]. Clusters of five to six cobalt atoms were reported in the mezopores of Co/MCM-41 by Jentys et al. [12].

There are many studies on the $\mathrm{CoCl}_{2}$ and silica interactions. Commercial silica gel [2], homemade silica gel [13], quartz [14] and silica hydrogel [4] were used for the production of $\mathrm{Co}$ (II)-silica system. Studies about interactions of silica particles having a wide range of surface area and different pretreatment procedures with $\mathrm{Co}$ (II) solutions of varying concentrations are present in the literature. The exact composition of the indicating silica gel was not reported in any of those.

The water vapor adsorption isotherm of the indicating silica gel was found as linear from saturated salt solution experiments. The same silica gel were used in studying column dynamics. Effects of the packing height, particle size, air velocity on breakthrough curves were determined [1].

Study of water vapor adsorption to indicating silica gels under static and dynamic conditions is the aim of this study. Indicating silica gels were prepared and their interaction with water vapor was evaluated in terms of their colour change, moisture adsorption and heat of desorption.

\section{Materials and the method}

$\mathrm{CoCl}_{2} \cdot 6 \mathrm{H}_{2} \mathrm{O}$ (reagent grade, Merck) and water glass (Akdeniz Kimya) and sulfuric acid were used in the experiments.

Silica hydrogels at $\mathrm{pH} 1$ containing $\mathrm{SiO}_{2}$ were prepared from water glass and sulfuric acid as described previously [15]. The silica hydrogel was at pH 2 after washing for 15 times with equal volumes of distilled water from by product sodium sulfate for $30 \mathrm{~min}$. They were aged in aqueous solutions having 0.008-0.42 mol dm${ }^{-3} \mathrm{CoCl}_{2}$ concentration for one week. The equilibrium $\mathrm{pH}$ of the solution was 1.6. $\mathrm{Co}(\mathrm{II})$-impregnated silica hydrogels were dried at $150^{\circ} \mathrm{C}$ till constant weight were obtained. From the material balance, concentration of $\mathrm{CoCl}_{2}$ in the samples was calculated. Keeping in $75 \%$ relative humidity $(\mathrm{RH})$ air at $25^{\circ} \mathrm{C}$ humidity for 1 day and redrying at $150^{\circ} \mathrm{C}$ were carried out to have homogeneous distribution of the salt on the surface of the silica gel.

Pellets in $2 \mathrm{~cm}$ diameter and $2 \mathrm{~mm}$ thickness were prepared from finely ground $\mathrm{CoCl}_{2}$-containing silica gels in dry form and in equilibrium with $30 \% \mathrm{RH}$ atmosphere at $25^{\circ} \mathrm{C}$ by using a hydraulic press operating at $3.18 \mathrm{MPa}$ pressure. The remission spectra at the pellets were taken as soon as they were prepared using Data Color Texflash DC 3881 visible spectro- 
photometer kept in $30 \% \mathrm{RH}$ atmosphere at $25^{\circ} \mathrm{C}$. The weight gain of the samples with $1.64 \mathrm{~mol} \mathrm{dm}^{-3}$ $\mathrm{CoCl}_{2}$ were also measured together with its spectrum at various time intervals.

The DSC analysis of the samples in equilibrium with $30 \% \mathrm{RH}$ atmosphere at $25^{\circ} \mathrm{C}$ were made by heating them $10^{\circ} \mathrm{C} \mathrm{min}^{-1}$ rate from 25 to $250{ }^{\circ} \mathrm{C}$ using Setaram DSC 92 under nitrogen flow rate of $75 \mathrm{~cm}^{3} \mathrm{~min}^{-1}$. The mass loss in samples were determined by weighing them before and immediately after heating.

Adsorption isotherm measurements at $25^{\circ} \mathrm{C}$ were carried out by using an automated instrument, Coulter Omnisorp $100 \mathrm{CX}$, using static dosing method. After each vapor dosing, the pressure of the system was continuously monitored at 10 -s intervals. When the difference between two subsequent measurements was less than $0.4 \%$, it was accepted that the system reached the equilibrium state. Helium evacuation time during volume calibration was $45 \mathrm{~min}$. The samples were out gassed $2 \mathrm{~h}$ at $10^{-4}$ mbar at $150^{\circ} \mathrm{C}$ before each adsorption experiment.

The experimental set up shown in Fig. 1 was used in dynamic column experiments. Air at $25^{\circ} \mathrm{C}$ and humidified to $85 \% \mathrm{RH}$ was send to silica gel packed column at rates in the range of $0.02-0.30 \mathrm{~cm} \mathrm{~s}^{-1}$. The column diameter and the packing height were 1 and $11 \mathrm{~cm}$, respectively. The silica gel used as the packing material with $1.66 \mathrm{~g} \mathrm{~cm}^{-3}$ apparent density, $0.85 \mathrm{~cm}$ particle size and containing $0.16 \mathrm{~mol} \mathrm{dm}^{-3}$ $\mathrm{CoCl}_{2}$ was dried at $150^{\circ} \mathrm{C}$ at atmospheric pressure before each experimental run. The displacement rate of the blue to pink front through the column was observed with bare eyes for different flow rates of air. The humidity of the outlet stream was measured with a calibrated hair hygrometer.

\section{Experimental results and discussion}

\subsection{Colour transition from blue to pink}

Quantitative description of the colour change of the samples was achieved through visible spectroscopy. Remission spectra was efficiently used for the identification of species in opaque samples. Although the peak maxima obtained in remission spectrum can be different than transmission spectrum [9] approximate results can be reached. The remission spectra obtained by using Data Color spectrophotometer was converted to absorbance spectra using Eq. (1)

$A=\log 100 / R$

where $R$ and $A$ are remission and absorbance, respectively.

Silica gel with $0.16 \mathrm{~mol} \mathrm{dm}^{-3} \mathrm{CoCl}_{2}$ in dry form have adsorption maxima at 660,570 , and $520 \mathrm{~nm}$ (Fig. 2) resembling the one observed by Hataway and Lewis [2] for $\mathrm{Co}\left(\mathrm{NO}_{3}\right)_{2}$-impregnated silica gel. Since similar spectra were observed for $\mathrm{CoCl}_{2}-$ and $\mathrm{Co}\left(\mathrm{NO}_{3}\right)_{2}$-containing gels, the strong interactions between the $\mathrm{Co}$ (II) and surface oxygens is the cause of the blue colour of the gels. The change of $\mathrm{CoCl}_{2}-$ containing silica gel spectrum with time in $30 \% \mathrm{RH}$

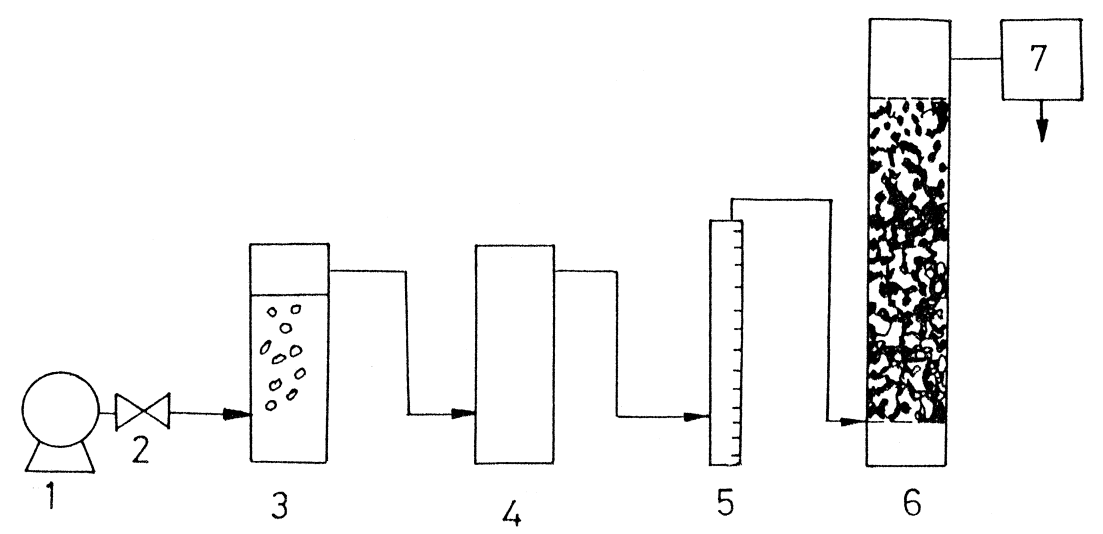

Fig. 1. Set up for dynamic column experiment: (1) air pump, (2) control valve, (3) saturator, (4) mist eliminator, (5) flow meter, (6) silica gel packed column and (7) hygrometer. 


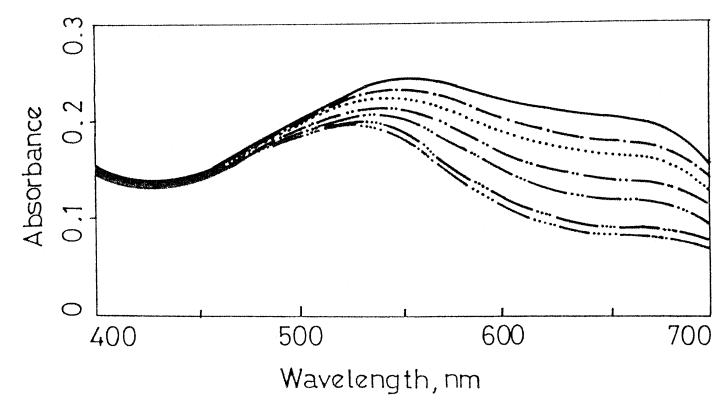

Fig. 2. Visible spectrum of $\mathrm{CoCl}_{2}$-containing silica gel with 1.64 mol dm ${ }^{-3} \mathrm{CoCl}_{2}$ in $30 \% \mathrm{RH}$ at $25^{\circ} \mathrm{C}$ air at $0-, 1 \cdot-, 2 \cdots$ $5 \cdots-, 10 \cdots-, 30 \cdots-, 60 \cdots-$ min contact time.

air (Fig. 2) indicates that with the adsorption of moisture the transition to $\mathrm{Co}\left(\mathrm{H}_{2} \mathrm{O}\right)_{6}^{++}$occurs in 60-min contact time. While the absorbance at 570 $\mathrm{nm}$ decreased, the weight gain of the sample increased linearly with square root of the time as seen in Fig. 3, showing colour and moisture relation of the $\mathrm{CoCl}_{2}$-containing silica gels.

Absorbance at $570 \mathrm{~nm}$ for dry and $520 \mathrm{~nm}$ for moisture adsorbed $\mathrm{CoCl}_{2}$-containing silica gels vs. concentration relation shown in Fig. 4 were linear. Silica gels having $0.047-0.284 \mathrm{~mol} \mathrm{dm}^{-3} \mathrm{CoCl}_{2}$ changed their colour from blue to pink upon moisture adsorption. Higher absorbance values or the darker colour of the blue form allows easy differentiation of the dry and the moist gels by human eye. The optimum $\mathrm{CoCl}_{2}$ concentration in indicating gels can be taken as $0.047 \mathrm{~mol} \mathrm{dm}^{-3}$.

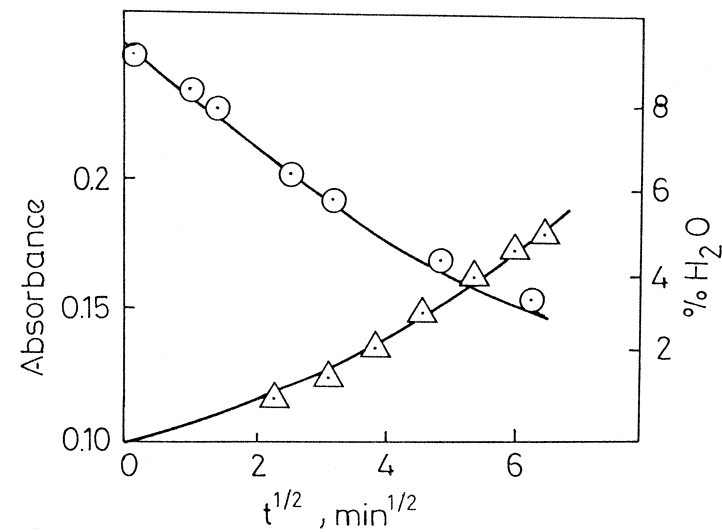

Fig. 3. Change of absorbance at $570 \mathrm{~nm}(\odot)$ and weight gain (triangle with dot inside) of $0.16 \mathrm{~mol} \mathrm{dm}^{-3} \mathrm{CoCl}_{2}$-containing silica gel vs. square-root of time in $30 \% \mathrm{RH}$ air.

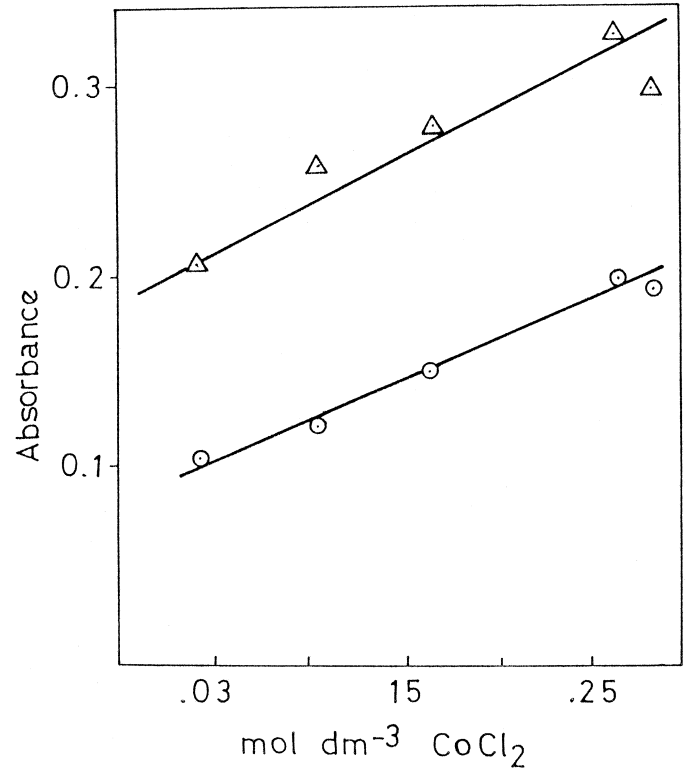

Fig. 4. Absorbance vs. concentration of $\mathrm{CoCl}_{2}$ in $\mathrm{CoCl}_{2}$-containing silica gel at $570 \mathrm{~nm}$ for dry (triangle with dot inside) at 520 $\mathrm{nm}$ for moisture adsorbed $(\odot)$ silica gels.

\subsection{Response of moist silica gel, $\mathrm{CoCl}_{2} \cdot 6 \mathrm{H}_{2} \mathrm{O}$ and moist $\mathrm{CoCl}_{2}$-containing gels to dynamic heating}

Adsorbed water of moist silica gels and $\mathrm{CoCl}_{2}-$ containing silica gels was removed by heating them up to $225^{\circ} \mathrm{C}$ as seen on their DSC curves (Fig. 5). Maniar et al. [16] observed similar behaviour in

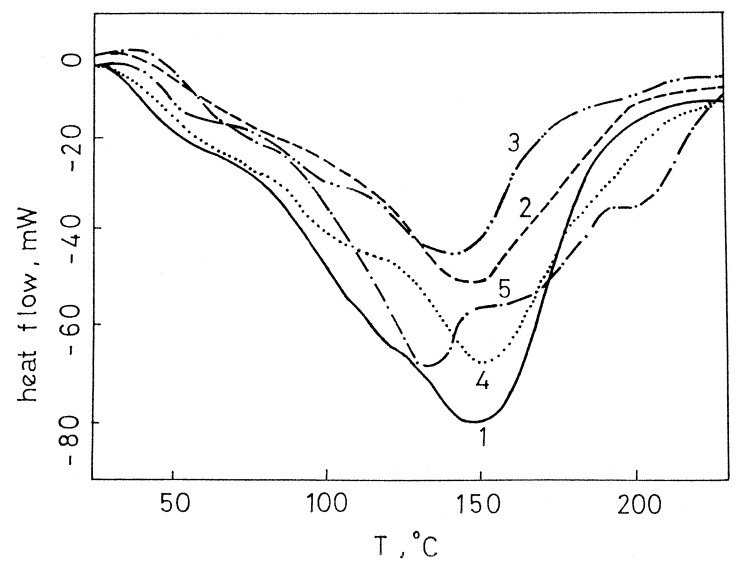

Fig. 5. DSC curves for (1) silica gel, (2) 0.18 , (3) 0.21 , (4) 0.28 , (5) $1.26 \mathrm{~mol} \mathrm{dm}^{-3} \mathrm{CoCl}_{2}$-containing silica gels. 
Table 1

Properties of the $\mathrm{CoCl}_{2}$-containing and control silica gels

\begin{tabular}{lllllllll}
\hline $\begin{array}{l}\mathrm{CoCl}_{2} \text { conc. } \\
\left.(\mathrm{mol} \mathrm{dm})^{-3}\right)\end{array}$ & $\begin{array}{l}\mathrm{CoCl}_{2} \text { conc. } \\
(\%)\end{array}$ & $\begin{array}{l}\text { Observed } \\
q \text { at } 60 \% \\
\mathrm{RH}(\%)\end{array}$ & $\begin{array}{l}\text { Predicted } \\
q \text { at } 60 \% \\
\mathrm{RH}(\%)\end{array}$ & $\begin{array}{l}\% \text { Reduction } \\
\text { in adsorption } \\
\text { capacity }\end{array}$ & $\begin{array}{l}T_{\max } \\
\left({ }^{\circ} \mathrm{C}\right)\end{array}$ & $\begin{array}{l}\Delta H_{\mathrm{d}} \\
(\mathrm{J} / \mathrm{g})\end{array}$ & $\begin{array}{l}\text { Total pore } \\
\text { volume } \\
\left(\mathrm{cm}^{3} \mathrm{~g}^{-1}\right)\end{array}$ & $\begin{array}{l}\mathrm{BET} \\
\text { surface } \\
\left(\mathrm{m}^{2} \mathrm{~g}^{-1}\right)\end{array}$ \\
\hline 0.00 & 0.00 & - & - & - & 150 & 2188 & 0.27 & 541 \\
$(\mathrm{~nm})$ & \\
0.18 & 1.53 & 20 & 24 & 22 & 140 & 2256 & 0.23 & 400 \\
0.21 & 1.97 & 20 & 25 & 18 & 150 & 1917 & 0.21 & 392 \\
0.28 & 2.40 & 19 & 25 & 24 & 150 & 2555 & 0.23 & 395 \\
1.28 & 11.00 & 18 & 25 & 28 & 130 & 2310 & 0.38 & 437 \\
\hline
\end{tabular}

sol-gel silicas. Table 1 shows, temperatures for peak maxima and integral heat of vaporization of $1 \mathrm{~g}$ of water from samples, $\left(\Delta H_{\mathrm{d}}\right)$, calculated from the areas of the peaks for water evaporation on DSC curves. While the observed peak temperatures were in the range of $130-150^{\circ} \mathrm{C}, \Delta H_{\mathrm{d}}$ changed between 1917-2555 $\mathrm{J} \mathrm{g}^{-1}$ and was at the order of heat of vaporization of free water. Although calculation of $\Delta H_{\mathrm{d}}$ from peak area of the DSC curve does not give an exact result due to heat capacity change of the sample during evaporation of water and weighing problems, it gives information about the order of the magnitude. Heat is taken during desorption and released during adsorption causing temperature changes affecting adsorption equilibrium. Heat of adsorption changes with the moisture of the solid and it is best determined using adsorption isotherms at different temperatures by making tedious experiments. Thus, finding the order of the magnitude of the integral heat of desorption which is the negative of the heat of adsorption by DSC analysis is a practical and useful method.

\subsection{Adsorption isotherms of water vapor on $\mathrm{CoCl}_{2}$, silica gel and $\mathrm{CoCl}_{2}$-containing silica gels}

The adsorption isotherm of water on $\mathrm{CoCl}_{2}$ at $25^{\circ} \mathrm{C}$ has two sharp steps which corresponds to the existence of $\mathrm{CoCl}_{2} \cdot 2 \mathrm{H}_{2} \mathrm{O}$ in the $\mathrm{RH}$ range of 12 to $34 \%$ and $\mathrm{CoCl}_{2} \cdot 6 \mathrm{H}_{2} \mathrm{O}$ in the 35 to $70 \%$ (Fig. 6). At relative humidities higher than $70 \%, \mathrm{CoCl}_{2} \cdot 6 \mathrm{H}_{2} \mathrm{O}$ takes up more water, forming aqueous solutions. The deliquescent behaviour of $\mathrm{CoCl}_{2} \cdot 6 \mathrm{H}_{2} \mathrm{O}$ at $\mathrm{RH}$ higher than $80 \%$ was also reported by previous workers [5]. From the adsorption isotherm of water on $\mathrm{CoCl}_{2}$ (Fig. 6) it is easily seen that the formation of $\mathrm{CoCl}_{2} \cdot 2 \mathrm{H}_{2} \mathrm{O}$ is completed at a $\mathrm{RH}$ of $15 \%$. Intense blue colour due to $\mathrm{CoCl}_{2}$ disappears at this $\mathrm{RH}$. On the other hand, the formation of pink $\mathrm{CoCl}_{2}$ - $6 \mathrm{H}_{2} \mathrm{O}$ is completed at $35 \% \mathrm{RH}$.

The adsorption isotherm of water vapor on silica gel is of type II of IUPAC classification (Fig. 7). The analysis of adsorption data gives BET surface area of $540 \mathrm{~m}^{2} \mathrm{~g}^{-1}$, pore volume of $0.27 \mathrm{~cm}^{3} \mathrm{~g}^{-1}$ and micropore volume of $0.20 \mathrm{~cm}^{3} \mathrm{~g}^{-1}$ (Table 1).

$\mathrm{CoCl}_{2}$-containing silica gels have nearly the same shape of adsorption isotherms with the pure silica gel in the RH range of $0-60 \%$. The amount of water vapor adsorbed to $\mathrm{CoCl}_{2}$-containing silica gel, $q$, can be predicted by using Eq. (2) if there are no interactions between them.

$q=x_{1} q_{1}+x_{2} q_{2}$

where $x_{1}$ and $x_{2}$ are the weight fractions of $\mathrm{CoCl}_{2}$ and silica gel, respectively. The $q_{1}$ and $q_{2}$ are the moisture adsorbing capacities of $\mathrm{CoCl}_{2}$ and the silica gel at the selected RH. The experimental amount of the water vapor adsorbed at $60 \% \mathrm{RH}$ were nearly

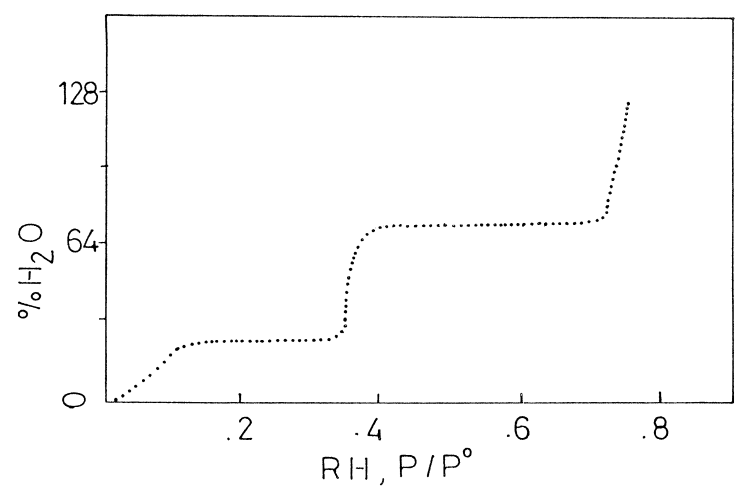

Fig. 6. Adsorption isotherm of water vapor on $\mathrm{CoCl}_{2}$ at $25^{\circ} \mathrm{C}$. 


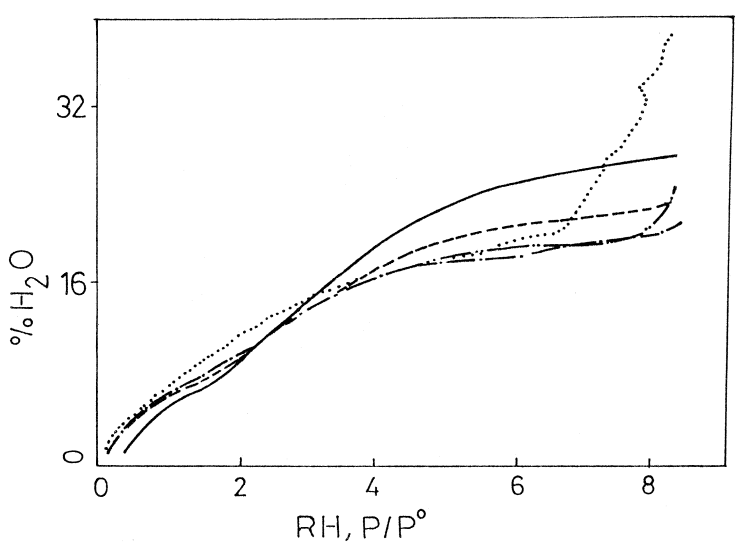

Fig. 7. Adsorption isotherm of water vapor on silica gel,- 0.18 ,$--- 0.21 \cdots-, 0.28 \cdot-, 1.26 \cdots \cdots \mathrm{mol} \mathrm{dm}^{-3} \mathrm{CoCl}_{2}$-containing silica gels.

$20 \%$ lower than predicted from Eq. (2) as seen in Table 1. Thus, presence of $\mathrm{CoCl}_{2}$ lowered the adsorption capacity of the silica gel by changing the pore structure of the gel. The silica gel containing $1.26 \mathrm{~mol} \mathrm{dm}^{-3} \mathrm{CoCl}_{2}$ shows a step increase in water vapor adsorption at around $70 \%$ RH (Figs. 6 and 7) could also be attributed to change of the pore structure of hydrogel in $\mathrm{CoCl}_{2}$ solutions. While enlarging of the pores of silica gel was reported by $\mathrm{Pal}$ et al. [17] in washing silica hydrogels with tap water containing dissolved polyvalent ions, Jentys at al. [12] obtained smaller pore volumes for $\mathrm{CoCl}_{2}$ containing MCM-41 than MCM-41 prepared under the same conditions. The surface area and total pore volumes reported in Table 1 were based on the change in pore structure of silica gel. BET surface area of $\mathrm{CoCl}_{2}$-containing gels were in the range of $392-437 \mathrm{~m}^{2} \mathrm{~g}^{-1}$. The $20 \%$ lowering of the surface area by the introduction of $0.18-1.28 \mathrm{~mol} \mathrm{dm}^{-3}$ $\mathrm{CoCl}_{2}$ may be due to formation of wider pores at the expense of smaller pores during aging in $\mathrm{CoCl}_{2}$ solutions. The average pore diameter $\left(d_{\mathrm{av}}\right)$ of the samples were calculated from total pore volume and surface area using Eq. (3) for cylindrical pores.

$d_{\mathrm{av}} / 4=($ Pore volume $/$ Surface area $)$

All the gels were microporous and the Co(II)silica gel samples all have larger diameter pores than the control silica gel as seen in Table 1. While the control sample has average pore size of $0.98 \mathrm{~nm}$, the $\mathrm{Co}$ (II)-silica gels have pore diameters in the range of 1.06-1.16 nm for the $\mathrm{CoCl}_{2}$ concentration 0.18 $0.28 \mathrm{~mol} \mathrm{dm}^{-3}$. Larger pores $(1.72 \mathrm{~nm})$ were obtained when $\mathrm{CoCl}_{2}$ concentration is $1.28 \mathrm{~mol} \mathrm{dm}^{-3}$.

\subsection{Water vapor adsorption kinetics}

\subsubsection{Static tests}

Although the chemical reaction between $\mathrm{CoCl}_{2}-$ containing silica and water vapor is a fast reaction, the transfer of $\mathrm{H}_{2} \mathrm{O}$ from vapor phase to the solid surface and into the pores of the gels controls the rate of colour inversion from humid air. In static moisture adsorption tests of silica gels, $60 \mathrm{~min}$ were required for the colour change (Fig. 2). The linear relation between uptake of water by indicating silica gel and the square-root of time shown in Fig. 3 confirmed the pore diffusion control of the moisture transport.

\subsubsection{Column dynamics}

The flowing gas experiments in the column allows refreshing the external surface of the packing with water vapor, thus only transfer rate of water vapor in the pores of silica gel is the rate controlling step. A sharp boundary was observed between the blue and pink regions of the column in flowing gas experiment with small air rates. The boundary become more diffuse at high air velocities. A linear

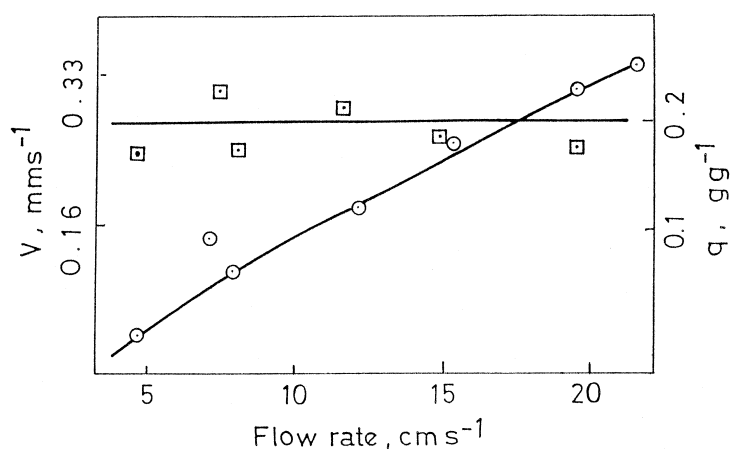

Fig. 8. Rate of boundary transport, $v(\odot)$ and the amount of adsorbed water at the end of each run (square with dot inside) vs. linear flow rate of air through the column. 


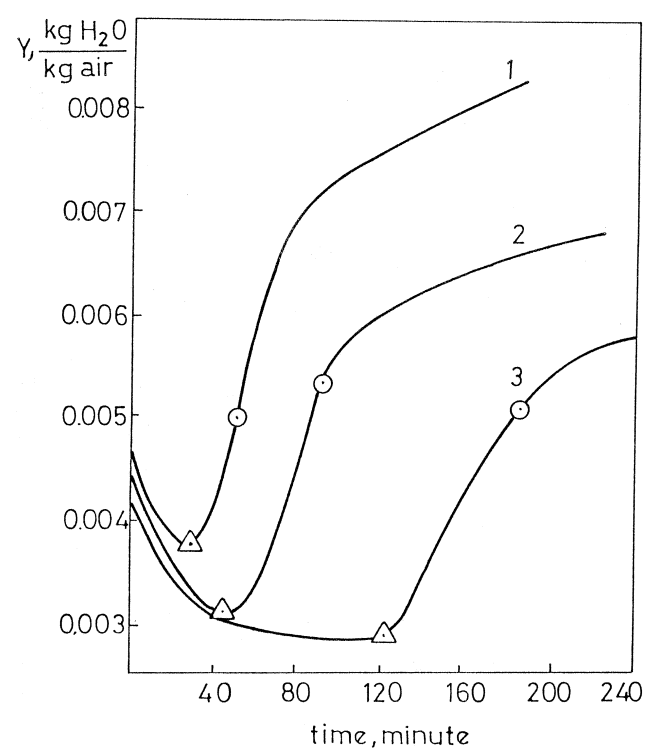

Fig. 9. Breakthrough curve from the column for (1) $5.5 \mathrm{~cm} \mathrm{~s}^{-1}$, (2) $2.6 \mathrm{~cm} \mathrm{~s}^{-1}$, (3) $1.7 \mathrm{~cm}^{-1}$ air velocity, triangle with dot inside: $\theta_{\mathrm{b}} ; \odot: \theta_{\mathrm{i}}$.

relation between the velocity $(v)$ of the boundary and air flow rate of $4.7-18.5 \mathrm{~cm} \mathrm{~s}^{-1}$ range was observed (Fig. 8). It was assured that no air channelling occurred in obtaining the breakthrough curves, by observation of the colour change of the entire column. The breakthrough curves from the column, absolute humidity $(Y)$ of the exit stream vs. time (Fig. 9) show the break points $\left(\theta_{\mathrm{b}}\right)$ at which the humidity of outlet stream starts to increase. The column should be regenerated at this point to get dry air from the column. The time required for the colour of the column become entirely pink $\left(\theta_{\mathrm{i}}\right)$ lags the break time. The solid's moisture calculated from the area between the inlet humidity and breakthrough curves between zero and $\theta_{\mathrm{i}}$, is around $9 \%$. The weight gain of the samples at the end of the column experiments was nearly $20 \%$ conforming the adsorption capacity measured by static volumetric adsorption methods. Since the colour change depends on the moisture of the solid, and the change of the moisture of the solid is a slow pore diffusion controlled process care should be paid to leave a safe limit of blue region, when indicating silica gel is used for monitoring regeneration times of the columns.

\section{Conclusion}

Quantitative data related to effects of $\mathrm{CoCl}_{2}$ on silica gel were obtained in this study.

Well-defined silica gels which are capable of adsorbing $20 \%$ moisture in $75 \% \mathrm{RH}$, showing colour inversion from blue to pink when its moisture is $9 \%$, having $392-437 \mathrm{~m}^{2} \mathrm{~g}^{-1}$ surface area and $0.21-0.37$ $\mathrm{cm}^{3} \mathrm{~g}^{-1}$ pore volume and having an average particle size of $3 \mathrm{~mm}$ were obtained by aging silica hydrogel in aqueous $\mathrm{CoCl}_{2}$ solutions. The indicating property of silica gel was obtained by a sacrifice from its adsorption capacity around $20 \%$.

They give off all of their adsorbed water at nearly $150^{\circ} \mathrm{C}$ by absorbing a quantity of heat in the range $1917-2555 \mathrm{~J} \mathrm{~g}^{-1}$ as determined by DSC.

Using the automated volumetric gas adsorption system at the present study it was possible to determine the correct adsorption isotherms of the samples. The adsorption isotherm was not linear [1], it was type II isotherm. Adsorption isotherm of water vapor on $\mathrm{CoCl}_{2}$-containing silica gel showed the pore structure of the silica gel was affected by the presence of $\mathrm{CoCl}_{2}$. Total surface area and the total pore volume were decreased due to aging in $\mathrm{CoCl}_{2}$ solutions.

When monitoring the regeneration time of an industrial column filled with Co(II)-silica gel, it will be safe to start regeneration before the entire column turn pink,considering slow diffusion controlled adsorption of water vapor.

The water vapor adsorption to indicating silica gel was studied using kinetic and equilibrium approaches. The adsorption isotherm and the heat of adsorption data obtained can be used in predicting column dynamics.

\section{References}

[1] D. Balköse, H. Baltacığlu, F. Abugaliye, Drying Technol. 8 (1990) 367.

[2] B.J. Hataway, C.E. Lewis, J. Chem. Soc. Inorg. Phys. Ther. (1969) 1183.

[3] L. Charlet, A. Monceau, Geochim. Cosmochim. Acta 58 (1994) 2577.

[4] G.M. Kesereva, V.M. Shamrikov, V.F. Malkiman, N.G. Belotserkovskaya, D.F. Gobychin, USSR Appl. Chem. 4 (1987) 882. 
[5] A.P. Russel, K.S. Fletcher, Anal. Chim. Acta 170 (1985) 209.

[6] F. Boltinghouse, K. Abel, Anal. Chem. 61 (1989) 1863.

[7] A.B. Lever, Inorganic Electronic Spectroscopy, Elsevier, New York, 1984.

[8] I. Ferguson, T.E. Wood, Inorg. Chem. 14 (1975) 180.

[9] I. Ferguson, T.E. Wood, Inorg. Chem. 14 (1975) 190.

[10] H.W. Joy, N. Fogel, J. Phys. Chem. 79 (1975) 345.

[11] Y.C. Xie, Y.Q. Tang, J. Catal. 37 (1990) 1.

[12] A. Jentys, N.H. Pham, H. Vinek, M. English, J.A. Lercher, Microporous Mater. 6 (1996) 13.
[13] D.F. Dobychine, N.G. Belotserkovskaya, V.M. Shamrikov, G.M. Keserava, Zh. Prikl. Khim. 59 (1986) 2434.

[14] T.W. Healy, R.O. James, R. Cooper, Adsorption from Aqueous Solutions, in: W.S. Weber, E.S. Matjevic (Eds.), Am. Chem. Soc., Washington, 1968.

[15] H. Baltacioğlu, D. Balköse, Colloid Polym. Sci. 267 (1989) 460.

[16] P.D. Maniar, A. Navrosky, E.M. Rabinovitch, J.Y. Ying, J. Non-Cryst. Solids 124 (1990) 101.

[17] J.B. Pal, T. Saran, L.V. Ramachadran, P.N. Mukherjee, Fuel Sci. Tech. 3 (1984) 23. 